Supplemental digital content for O'Brien CL, Sanguino SM, Thomas JX, Green MM. Feasibility and outcomes of implementing a portfolio assessment system alongside a traditional graded system. Acad Med. 


\section{Curricular structure of the Northwestern University Feinberg School of Medicine}

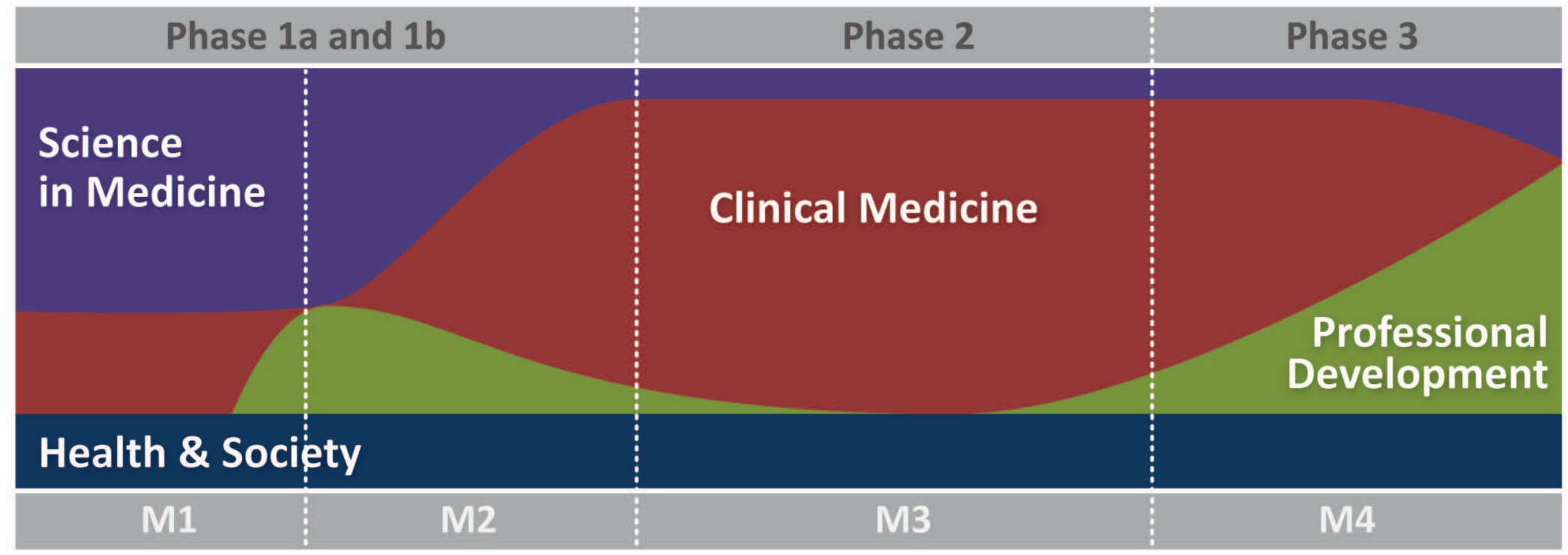

